\title{
MEGA KALAHARI GEOLOGY: CHALLENGES OF KIMBERLITE EXPLORATION IN THIS MEDIUM
}

\author{
Clint Williams ${ }^{1}$, Brett van Coller ${ }^{1}$, Tom Nowicki ${ }^{2}$ and John Gurney ${ }^{1}$ \\ ${ }^{1}$ Mineral Services South Africa Pty Ltd, Cape Town.; ${ }^{2}$ Mineral Services Canada Inc, Vancouver.
}

\section{INTRODUCTION}

In southern Africa the name Kalahari refers to a structural basin, a group of terrestrial continental sediments and an ill-defined desert, all of which are intimately linked yet also possess distinct characteristics. The surface units of the Kalahari Group cover represent the worlds largest body of sand covering over 2.5 million $\mathrm{km}^{2}$ of central and southern Africa from the Orange River at $29^{\circ} \mathrm{S}$ to $1^{\circ} \mathrm{N}$ in the western Congo and southern Gabon (Thomas, 1988),(Figure 1). Thomas and Shaw (1990) grouped all these sediments together under the term Mega Kalahari. This term has been adopted for the review.

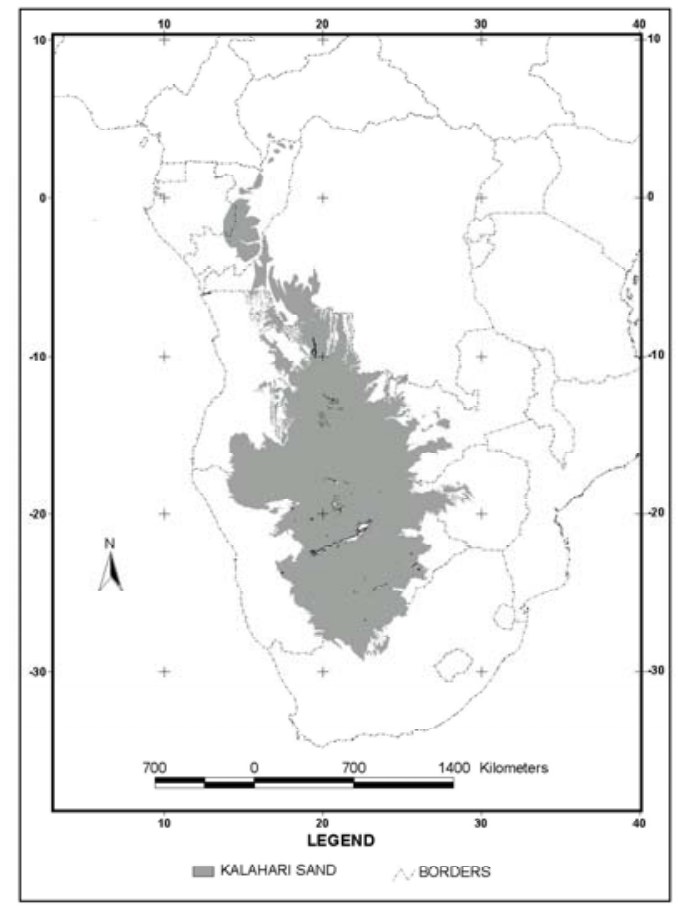

Figure 1. Distribution of the Mega Kalahari in central and southern Africa

Approximately 1.6 million $\mathrm{km}^{2}$ of Mega Kalahari lie directly over cratonic crust that is prospective for diamond-bearing kimberlites. This presents formidable obstacles and challenges to the kimberlite explorationist attempting to locate bedrock-hosted diamondiferous kimberlite bodies. The paper presents the complexities of this cover sequence, with a view to formulating improved kimberlite exploration strategies in this environment.

\section{CHARACTERISTICS}

The Mega Kalahari sediments represent an ancient depositional environment with a complex history in which the stratigraphy and age of the deposits are not particularly well constrained or understood. Low fossil content, limited exposure, poor differentiation of the dominant surficial Kalahari Sand and a limited comprehension of an extensive duricrust suite has delayed the understanding of the sedimentological and environmental history of the basin.

Collectively the sediments are referred to as the Kalahari Group (SACS, 1980). SACS (1980) distinguished 6 major lithological types in the Kalahari Group: conglomerate and gravel, marl, sandstone, alluvium and lacustrine deposits, Kalahari Sand, and duricrusts (mainly calcrete and silcrete).

\section{GEOMORPHIC EVOLUTION}

Key factors and complexities important in the evolutionary framework of the Kalahari Basin include development of the basin following the fragmentation of Gondwanaland, sub-continent drainage development, climatic change and post depositional modification. Table 1 provides a summary of the major events.

This sequence of sediments accumulated and evolved through fluvio-deltaic, aeolian and groundwater processes, with characteristics due to primary deposition and subsequent modification being difficult to distinguish. Deposition in the Kalahari Basin has been subject to tectonic influences, changes in drainage directions and source areas of sediments, river capture and numerous large and small climatic fluctuations both in the basin and surrounding areas. It bears the imprint 
Table 1. : Major events in the evolution of the Kalahari after Thomas and Shaw (1993)

\begin{tabular}{|c|c|c|c|}
\hline Period & Epoch & $\mathrm{Ma}$ & \\
\hline \multirow[t]{3}{*}{ Quaternary } & Holocene & 0.01 & $\begin{array}{l}\text { Development of major landform suites in surface sediments } \\
\text { Continued subsidence in Okavango Rift }\end{array}$ \\
\hline & Pleistocene & 2 & Establishment of modern course of Zambezi River \\
\hline & Pliocene & 5 & Deposition of Kalahari sediments throughout Tertiary; progressive \\
\hline \multirow[t]{5}{*}{ Tertiary } & Miocene & 22 & capture of endoreic rivers; further uplift of escarpment. \\
\hline & Oligocene & 38 & \\
\hline & Eocene & 55 & Deposition of lower Kalahari Group sediments in interior basin by \\
\hline & Palaeocene & 65 & endoreic rivers \\
\hline & & 80Ma & Full marine conditions in South Atlantic \\
\hline Cretaceous & & 130Ma & Initial opening of the South Atlantic \\
\hline & & 136 & $\begin{array}{l}\text { Major phase of rifting and initiation of the hinge line and great } \\
\text { escarpment }\end{array}$ \\
\hline Jurassic & & 180Ma & Separation of Antarctica from eastern margin of southern Africa \\
\hline & & 195 & \\
\hline Triassic & & 200Ma & Beginning of Gondwana break-up \\
\hline
\end{tabular}

of recurring cycles during which the same sediments were reworked, sometimes by different agencies, all of which exacerbate attempts to correlate sedimentary units across the sequence (Thomas and Shaw, 1993).

The Mega Kalahari is a Phanerozoic sedimentary basin situated within the African Superswell. The Superswell has dominated the gross geomorphology of southern Africa and contributed significantly to the present character of the Mega Kalahari (Burke, 1996; Partridge, 2000). Overall, the tectonic framework established in southern Africa by the division of Gondwanaland led to the creation of a dual drainage system, with the hingeline (current day escarpment) acting as a watershed between a coastally-orientated exoreic system and an endoreic system draining into the interior (Moore, 1998). Deposition of sediments started in the late Cretaceous. Neo-tectonic rifting in central Botswana, further influenced sedimentation rates and exerted a strong control over paleo-drainage directions (Thomas and Shaw, 1992; Moore 1998).

\section{KIMBERLITE EXPLORATION IN THIS MEDIUM}

\section{KIMBERLITES BENEATH tHE MEgA KaLAHARI}

Southern Africa contains the highest known concentration of kimberlites in the world, in excess of 850 occurrences (Figure 2). These include the world class economic Orapa and Jwaneng deposits within the central Kalahari of Botswana.

The age of intrusion for southern African pipes varies from the mid-Proterozoic to the mid-Cretaceous spike at 80-120 Ma. As the Kalahari is not considered to be older than late Cretaceous, and more probably early Tertiary (Paleocene), this succession should post-date and overly all kimberlites. The possibility of synKalahari pipes is not excluded but merely considered unlikely.

\section{IMPLICATIONS FOR KIMBERLITE EXPLORATION STRATEGIES}

Kimberlite exploration in areas of deep surficial cover and transported overburden is a demanding exercise. When designing and implementing kimberlite exploration programs in the Mega Kalahari environment the most important geomorphological and sedimentary factors to be considered are presented below:

\section{Tectonic framework and structural background}

The Mega Kalahari occupies a series of contiguous Phanerozoic sedimentary basins. The position and controls of these basins can be broadly correlated with the mantle-plume "sub swells" described by Burke (1996) and Cox (1989). The location of the area of interest must be considered in the context of these large, regional basins and the characteristics of these basins as well as any similarities or differences that may exist between them.

\section{Mega Kalahari thickness}

Exploration drilling in the Mega Kalahari has shown significant variability in its thickness from local to 


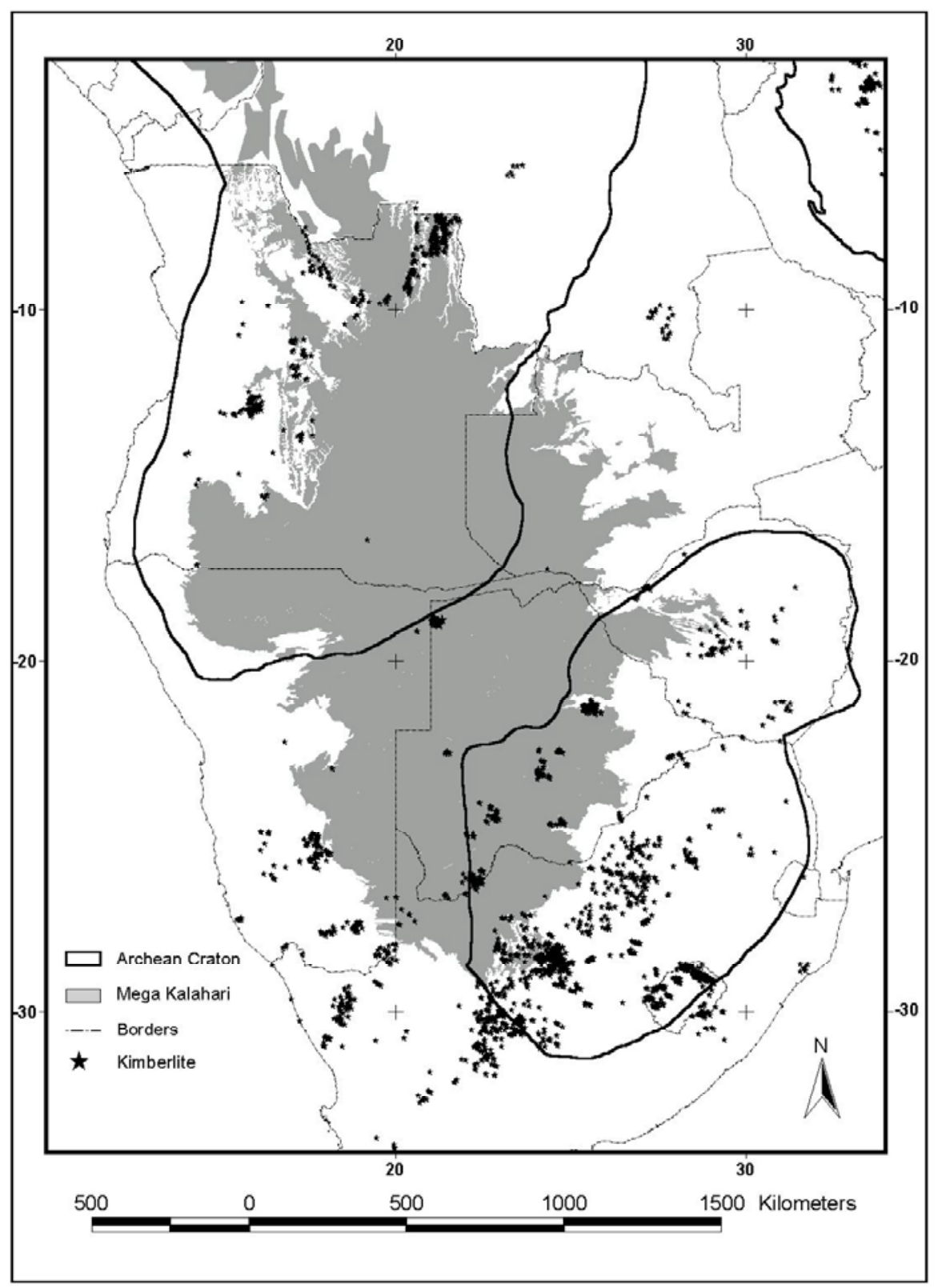

Figure 2. Mega Kalahari sediments overlying known craton and kimberlites

regional scales. This cannot be attributed to surface topographical variations, since the sub-continental interior is an area of markedly low relief. Nor is it simply the result of decreasing thicknesses of sediments towards the rim of the interior basin. Some of the variation in thickness can be attributed partly to recent, relatively minor rifting in the central Mega Kalahari. However, it is believed that the bulk of the variation can be attributed to the relief of the pre-Mega Kalahari surface. The thickness of the Mega Kalahari in any area of interest is critical information for the exploration program as it has a direct influence on the mobility, dispersion and dilution of kimberlitic indicator anomalies as well as the sensitivity and resolution of geophysical applications and the modeling of these results. The negative impact on these factors increases with increasing thickness. .

\section{Lithological variations}

Whilst gross similarities in lithological types between the structural basins can be expected, caution should be exercised in assuming any major correlations and 
extrapolations. A well sorted, quartz rich sand of predominantly aeolian origin can be expected as the surface expression of the Mega Kalahari. Magnesiumrich ilmenite and mantle derived garnets are typically the most common kimberlitic heavy minerals targeted and recovered in the semi-arid sandveld environments of the Mega Kalahari. The sands overlie repetitive layers of duricrusts, predominantly pedogenic calcretes.

Whilst drilling is typically a final tool in exploration programs it can be a prudent step in the middle to late stages in programs within the Mega Kalahari. This is particularly relevant where local information on Kalahari thickness and lithology types are scarce or absent. It may also reveal the presence of any secondary, fluvio-gravel horizons rich in heavy minerals.

\section{Pre-Kalahari bedrock}

Pre-Mega Kalahari bedrock type can significantly affect the application of certain key geophysical techniques. Areas of the Mega Kalahari underlain by rock types with high magnetic susceptibility and variability (Karoo basalts, metamorphic gneiss terranes) present considerably greater difficulties for kimberlite identification than areas underlain by magnetically "quiet" bedrock types. In magnetically uniform areas, magnetics is a highly effective tool. Gravity is a useful follow-up technique and discriminator for discrete magnetic targets. Electrical methods are best applied in relatively thinner parts $(<60 \mathrm{~m})$ of the Mega Kalahari. The nature of the bedrock type is important in constraining certain physical properties of the rock for geophysical modelling of data generated by magnetic, gravity and electrical methods.

\section{Drainage and aeolian patterns}

It is imperative to understand the existing drainage patterns in an area of interest and how these relate to the evolution of the Mega Kalahari endoreic drainage systems since the disruption of Gondwana. These drainage patterns may allow reconstruction of kimberlitic heavy mineral indicator dispersion histories, which are vital to the kimberlite explorationist. The distribution histories are complicated in many cases by a combined fluvial-aeolian history. Primary processes of deposition and subsequent modifying process are difficult to distinguish. Fluvial and aeolian processes in the Kalahari, whether alone or in combination, are capable of transporting heavy minerals across hundreds of kilometers in the Mega Kalahari environment and creating anomalies attributed to non-primary sources.
Partridge (2000) and Moore (1998, 1999) have provided compelling reconstructions of the drainage evolution of the Mega Kalahari since the break-up of Gondwana.

Extensive paleo-dune patterns within the Mega Kalahri provide indications of paleo-wind directions, which must be factored into the transport history of heavy mineral anomalies. Current prevailing wind patterns should not be ignored and may currently be influencing the dispersion of heavy minerals.

\section{REFERENCES}

Burke, K. (1996). The African Plate. South African Journal of Geology., 99: 341-409.

Cox, K.G. (1989). The role of mantle plumes in the development of continental drainage patterns. Nature, 342. $873-877$

Janse, A.J.A. (1995). A history of diamond sources in Africa. Gems and Gemology, PartI, Winter 1995, pp. 288-255.

Moore, A.E. \& Dingle, R.V. (1998). Evidence for fluvial sediment transport of Kalahari sands in central Botswana. South African Journal of Geology. 101,143.

Partridge, T. C. \& Maud, R. R. (2000). Macro-Scale geomorphic evolution of Southernn Africa. In: The Cenozoic of Southern Africa. (eds T.C. Partridge and R.R. Maud). Oxford University Press, 406 pp.

SACS (1980). Stratigraphy of South Africa. Part 1. Handbook of geological survey of South Africa: 690 pp.

Thomas, D. S. G. (1988), The nature and depositional setting of arid and semi-arid Kalahari sediments, Southern Afr.. Journ. Arid Environ. 14, 17-26.

Thomas, D. S. G. \& Shaw, P.A. (1993). The evolution and characteristics of the Kalahari, southern Africa. Journal of Arid Environments. 25, 97-108.

Contact: C. Williams, PO Box 38668 Pinelands, 7430, Cape

Town, RSA. E-mail: clint.williams@minserv.co.za 